\title{
A CONSTRUÇÃO DE RECURSOS DIDÁTICOS NAS AULAS DE GEOGRAFIA: PERCEPÇÕES DE ESTUDANTES DE PÓS- GRADUAÇÃo
}

\author{
The construction of teaching resources in geography lessons: perceptions of powership \\ students \\ Adilson Tadeu basquerote Silva* \\ Eduardo Pimentel Menezes ${ }^{* * *}$ \\ Rozemy da Silva Nascimento ${ }^{* * *}$ \\ * Dotorando em Geografia - UFSC - abasquerote@yahoo.com.br. \\ ** Docente nos PPG em Geografia - UERJ - epmenezes30@gmail.com. \\ ***Docente no PPG em Geografia -UFSC - rosemy.nascimento@gmail.com. \\ 08/08/2018. Aceito para publicação em 25/08/2018. \\ Versão online publicada em 20/11/2018 (http://seer.ufrgs.br/paraonde)
}

\begin{abstract}
Resumo: 0 presente estudo analisa a percepção de estudantes a respeito da construção, em sala de aula, de recursos didáticos aplicados à educação geográfica na pós-graduação stricto sensu. Trata-se de um estudo de caso, de natureza qualitativa, com dados obtidos por meio de observação participante e entrevistas semiestruturadas realizadas com quinze estudantes que cursaram a disciplina de Recursos Didáticos plicados a Educação Geográfica e Ambiental (RDAEGA), no período de 2015 e 2016. Os dados estudados pela análise do discurso revelaram que a construção dos recursos emsala de aula facilita a compreensão dos conteúdos e conceitos, promove interação entre os envolvidos, torna as aulas mais atrativas e dinâmicas, alia ações integradoras entre teoria e prática, amplia o rol de recursos didáticos aplicados à educação geográfica e instrumentaliza os pós-graduandos a construírem recursos com seus estudantes.
\end{abstract}

Palavras-chave: Mediação; ensino; geografia.

\begin{abstract}
The present study analyzes the students' perception regarding the construction, in the classroom, of didactic resources applied to the geographic education in the stricto sensu post-graduate course. It is a case study of a qualitative nature with data obtained through Participant Observation and semistructured interviews with fifteen students who attended the course on Didactic Resources Applied to Geographical and Environmental Education in the period of 2015 and 2016. The data analyzed By the Discourse Analysis revealed that the construction of resources in the classroom facilitates the understanding of contents and concepts, promotes interaction among those involved, makes classes more attractive and dynamic, combines integrative actions between theory and practice, extends the role of didactic resources applied To geographic education and equips post-graduate students to build resources with their students.
\end{abstract}

Key-words: Mediation; teaching; geography.

\section{Introdução}

0 atual contexto escolar exige uma constante reflexão sobre o modo de pensar e fazer a Educação Geográfica. Neste sentido, as escolhas criteriosas do enfoque filosófico, o uso de diferentes linguagens e os procedimentos metodológicos adotados tornam a geografia escolar relevante, com sentido e significado. Nesta perspectiva, a análise e construção de recursos didáticos utilizados na sala de aula têm incitado pesquisas em diferentes componentes curriculares, e em especial, na Geografia.

Estudos de Almeida (2001) e Schäffer (2005) destacam a existência de um leque de materiais e recursos didáticos que possibilitam vivenciar experiências interessantes em sala de aula e favorecem a mediação entre o professor, o conhecimento e os estudantes. Segundo Fiscarelli (2008) recursos 
didáticos caracterizam-se como um conjunto de materiais que, empregados com finalidade pedagógica, auxiliam o processo de mediação. São exemplos: o livro didático, globo terrestre, maquetes, expressões corporais microcomputadores, Global Position System (GPS), entre outros. Para a autora,

Os materiais didáticos, antes simples objetos, passam a adquirir significados importantes na concretização e efetivação de novas propostas educacionais, direcionando e definindo nossas visões sobre o que é ser um bom professor, o que é dar uma boa aula, o que é ser uma boa escola e o que é melhor utilizado em sala de aula [...] (2008, p.22).

Nascimento (2007) complementa ao afirmar que os recursos didáticos, ou instrucionais, podem ser qualquer elemento utilizado como facilitador de um processo de assimilação de informação e geração de conhecimento, seja para diversão ou na educação. Quando este está sob a tutela da educação, tende a ter uma proposta metodológica voltada para o processo de ensino e aprendizagem de uma temática pré-determinada.

Neste sentido, a escolha e o uso dos recursos didáticos a serem utilizados em sala de aula vincula-se a opção metodológica do professor, que, ao agir criticamente, pode ampliar as possibilidades de aprendizado (ARCANJO et al., 2009). Nesta direção, Sacramento (2015, p. 11) destaca a importância da mediação pedagógica e das opções metodológicas tomadas pelo docente para a efetiva aprendizagem.

A ação docente está, portanto, relacionada aos caminhos didático-pedagógicos e educacionais na orientação dos saberes científicos em sala de aula, para promover uma aprendizagem significativa. Realizar uma prática mediática que contribua para a evolução conceitual dos alunos, refletindo sobre a realidade vivida por eles, respeitando suas histórias de vida e contribuindo para que entendam o seu papel na sociedade: o de cidadãos.

Estudos como os de Pontuschka, Paganelli e Cacete (2009), Goulart (2014), Cavalcanti (2011, 2012, 2014), Costella (2014), Tonini (2014), Nascimento (2007 e 2014) sinalizam a importância de atitude ativa do professor frente à adoção de novas metodologias no processo de mediação como forma de promover uma aprendizagem significativa. Neste sentido, o recurso didático utilizado contribui neste processo.

\section{POR ONDE ANDA O ENSINO DE GEOGRAFIA?}

Historicamente, o processo de mediação na Geografia Escolar no Brasil foi caracterizado pela fragmentação do saber e pelo afastamento da realidade cotidiana dos estudantes. Segundo Castrogiovanni (2014), "a Geografia foi considerada uma ciência das descrições e das localizações, ou seja, a Geografia do cubo". Na mesma direção, Cavalcanti (2010, p. 47) salienta que "o modo de trabalhar os conteúdos geográficos no ensino supera seu histórico papel de dar conta da apresentação de dados e da descrição de países, regiões e lugares mencionados".

Ao destacar a importância da geografia como componente curricular Kaercher (1999) afirma que, juntamente com outras disciplinas escolares, a Geografia pode ser um instrumento valioso para elevar a criticidade dos estudantes, pois trata de assuntos intrinsecamente polêmicos e políticos.

Como forma de superar a prática da simples de conceitos geográficos, Callai (2011), Azambuja (2011) pontuam que é necessário atuar a partir do contexto de vida dos estudantes. Em conjuntura semelhante, Cavalcanti (2013) e kaercher (2003) destacam a relevância dos conhecimentos cotidianos dos estudantes, especialmente a respeito do lugar onde vivem e suas representações sobre os diferentes lugares do globo. Kaercher (2007) destaca a necessidade de transformar a visão de que a geografia escolar é enfadonha, maçante e restrita aos livros e ao discurso do professor.

Baseado no exposto anteriormente urge a necessidade de mediação pedagógica no ensino de Geografia e um contínuo processo de ação-reflexão-ação (CASTROGIOVANNI, 2011). Para que isto aconteça, Callai (2011 defende que as aulas de geografia devem

[...] procurar com que os alunos consigam fazer as suas aprendizagens tornando 
significativos para as suas vidas estes mesmos conteúdos. [...] procurar construir as ferramentas teóricas para entender o mundo e para as pessoas se entenderem como sujeitos nesse mundo, reconhecendo a espacialidade dos fenômenos sociais (p. 15).

Nesta perspectiva, a Geografia tem procurado ampliar seu papel no processo de ensino e de aprendizagem, dentre outras formas, por meio da pesquisa e da discussão de novas metodologias e conteúdos e vem fomentando novas práticas didático-pedagógicas. Cavalcanti (2011, p. 81) afiança que "essa geografia, ao ser integrada no currículo da escola, contribui com a capacidade do trabalho docente de intervir nos motivos e interesses pessoais dos estudantes, com o objetivo de mediar seus processos de reflexão".

Pontuschka, Paganelli e Cacete (2009) afirmam que uma didática consistente pode aguçar a reflexão do estudante para produzir conhecimentos que não estão nos livros didáticos. Além disso, a relação didática atrelada ao contexto histórico e geográfico dá sentido ao processo de mediação geográfica. Nesta direção, Castrogiovanni (2003) defende que no ensino de geografia, "devem ser refletidos e teorizados espaços históricos e contraditórios, associando-os num constante movimento entre o vivido/percebido e o conceitual/teórico".

Reforçando o exposto, Goulart (2014) destaca que para efetivar a aprendizagem o processo de mediação deve promover diálogo com o conhecimento, estabelecer distintas conexões com os conceitos já construídos, sejam eles geográficos ou não. Assim, "as possibilidades de um trabalho significativo estão ligadas às questões de envolvimento e mobilização dos estudantes, mas a isso precisa estar associado o trabalho intencional que inclua a apreensão de conteúdos e habilidades que favoreçam as conexões" (p. 23).

Ademais, a contribuição da geografia, enquanto componente curricular, dependerá do processo de mediação que utilize os recursos didáticos adequados e que possibilitem o entendimento dos conteúdos e conceitos, promovendo aprendizagem significativa dos saberes geográficos.

\section{Procedimentos metodológicos}

Como forma de contextualizar o espaço de coleta de dados e os sujeitos da pesquisa, faz-se necessário apresentar sucintamente a disciplina de RDAEGA. Criada em 2007 sob a nomenclatura de "Recursos instrucionais aplicados à educação geográfica", é uma disciplina eletiva oferecida regularmente no primeiro semestre de cada ano e recebe estudantes regulares e especiais de mestrado e doutorado. Dispõe de uma carga horária total de 120 horas/aula, distribuídas em atividades práticas ( 90 horas) e estudos em teóricos (30 horas).

Dentre os estudos teóricos de educação geográfica e ambiental, destacam-se definições, tipos, potencialidades e limitações; a ciência e disciplina de geografia; educação ambiental formal e nãoformal; processos pedagógicos e andragógicos de ensino e aprendizagem. Já a confecção de recursos didáticos em sala de aula compreende: Recursos de cartografia (mapas, gráficos e diagramas, maquetes geográficas, globos, entre outros); Recursos das artes (desenho, pintura, escultura, música, teatro, cinema, vídeo, entre outros); Recursos do entretenimento científico (brinquedos, jogos e brincadeiras) Recursos de tecnológicos digitais (equipamentos, sistemas e ambientes).

Este estudo, por sua característica, apresenta-se de natureza qualitativa, por meio de um Estudo de Caso (YIN, 2001). Segundo Bogdan; Biklen, (1994) a pesquisa qualitativa acontece quando a fonte direta dos dados é o ambiente natural, sendo o pesquisador o principal instrumento devido ao contato prolongado e direto com o objeto de estudo.

Para coleta de dados foram realizadas quinze entrevistas semiestruturadas (FLICK, 2013) com estudantes de mestrado e de doutorado de um programa de pós-graduação em Geografia, de uma universidade pública do Sul do Brasil, que cursaram a disciplina de Recursos Didáticos Aplicados a Educação Geográfica e Ambiental (RDAEGA) no período de 2015 e 2016. Dos entrevistados, treze atuam como professores na Educação Básica, na Graduação e Pós-graduação. Complementaram-se os dados das entrevistas utilizando-se de observação participante (HAGETTE, 1995) realizada no primeiro semestre do ano de 2015 e de 2016. Para análise dos dados, utilizou-se o método da Análise do Discurso (ORLANDI, 2003).

ParaOnde!?, Porto Alegre, v.10, n.2, p.78-84, 2018. Edição Especial com artigos publicados originalmente na XII ENANPEGE http://seer.ufrgs.br/paraonde 


\title{
4. Resultados e discussão
}

$\mathrm{Na}$ atualidade, diferentes estudos tem buscado compreender o processo de ensino e de aprendizagem no contexto escolar. Segundo Castellar (2005, p.3), no âmbito da geografia faz-se necessárias "mudanças na postura do corpo docente em relação a como, para quê e para quem ensinar a geografia escolar". A autora enfatiza a necessidade de desenvolver novas metodologias de ensino, além estruturar melhor os conteúdos e definir claramente os objetivos de ensino. Nesta ótica, é necessário reestruturar o saber-fazer em sala de aula, buscando integrar os saberes geográficos com os saberes pedagógicos, desenvolvendo metodologias estimuladoras de ensino que reestruturem os conteúdos e que tenham com clareza os objetivos do ensino de tal disciplina. A fala do Estudante 1 avaliza o exposto acima ao destacar sua percepção sobre a importância de uma relação estimuladora, crítica e mediada por outros saberes evidenciada na construção dos recursos didáticos em sala de aula.

\begin{abstract}
Nossas aulas foram muito instrutivas. Defendo que, inclusive, na pós-graduação deve haver espaços para a construção de recursos didáticos em sala de aula. Pela experiência que tivemos na disciplina de RDAEGA, a professora nos orientava sobre a importância do recurso que a gente estava construindo e a sua aplicabilidade. A cada recurso que a gente construía, eu me sentia motivado a realizar uma nova construção, por que sabia que depois poderia também construir com meus próprios alunos a mesmo recurso e tornar minha prática pedagógica mais eficaz e significativa (Estudante 1, aluno de doutorado, 2015).
\end{abstract}

As constatações do Estudante 1 vão ao encontro dos estudos de Kaercher (2003), Nascimento (2014) e Castrogiovanni (2007, p. 46) quando destacam a importância da postura do professor em "considerar o aluno como sujeito". Sacramento (2014, p.37), enfatiza que, por meio de "metodologias inovadoras e ativas que provocam surpresas quando há descobertas e estimulam a elaboração de outros questionamentos, esses podem ser momentos de superação dos obstáculos de aprendizagem".

Ao defender a construção dos recursos didáticos em sala de aula na pós-graduação, o Estudante 6 avaliza os estudos de Martins (2014), Kaercher (2003), Sacramento (2014), Callai (2011), Cavalcanti (2014), entre outros, quando defendem uma aproximação do ensino de geografia à realidade concreta do estudante. A saber:

O que mais consideramos importante sobre esta disciplina é o caráter eminentemente prático que ela possui, embora não nos distanciamos da teoria. No início acreditamos que, por ser na pós-graduação, as aulas seriam com práticas genéricas, sem um adensamento conceitual. No entanto, percebemos que antes de cada recurso construído, era necessário todo o embasamento conceitual para possibilitar a sua construção. Por exemplo, construímos a maquete das Ilhas Irmãs e para isso, tivemos que estudar conceitos relacionados a curvas de nível, perfil topográfico, escalas, entre outros. Desta forma, além de facilitar a compreensão dos conteúdos e conceitos, as aulas se constituíram de forma dinâmica e interativas. (Estudante 6, aluna de doutorado, 2016).

Os depoimentos também evidenciaram que, além de facilitar a compreensão dos conceitos e conteúdos, a construção dos recursos em sala de aula promove maior interação entre os envolvidos e possibilita que os próprios estudantes criem ou construam seus instrumentos de aprendizagem. 0 depoimento do Estudante 10, expressa tal assertiva.

Construir os recursos na sala de aula promove uma maior interação entre os alunos e destes com professor. A sala de aula se transforma em uma oficina e um ajuda o outro durante as construções e ao mesmo tempo existe a mediação/intervenção do professor. Cria-se um espaço acolhedor, onde as dúvidas podem ser sanadas instantaneamente e temos a possiblidade de experimentar, criar, recriar, adaptar, fazer e refazer os recursos. Além disso, existe a possibilidade de usarmos materiais alternativos, que encontramos com facilidade, de baixo custo, ou até mesmo de reciclagem, como isopor, balões, massinha de modelar, barbante, entre outros. (Estudante 10, aluno de doutorado, 2015).

Para0nde!?, Porto Alegre, v.10, n.2, p.78-84, 2018. Edição Especial com artigos publicados originalmente na XII ENANPEGE http://seer.ufrgs.br/paraonde 
Estudante 11 reforça o estímulo que a construção dos recursos em sala de aula traz a mediação e o baixo custo dos materiais utilizados.

0 que move minha admiração pela construção em sala é a curiosidade que os recursos oferecem. A gente quer saber se vai dar certo, como eles vão ficar. A professora apresenta a proposta do recurso e a gente pode ir sugerindo mudanças no material a ser utilizado. Estas trocas são muito interessantes e tornam mais eficaz a aprendizagem. Sem contar que os materiais são de baixo custo, muitas vezes, reaproveitando embalagens que iriam para lixeira, como isopor, potes de sorvete, garrafa pet, por exemplo (Estudante 4, aluno de mestrado, 2015).

O depoimento anterior reforça os estudos de Castrogiovanni (2014), Costella (2014), Nascimento (2007 e 2014), Martins (2014), Tonini (2014), Cavalcanti (2014) e Callai (2014), entre outros, quando asseveram a necessidade do professor de geografia instrumentalizar o seu estudante a ser sujeito do seu próprio conhecimento. Nesta direção, além de destacar o protagonismo do estudante na construção do conhecimento, as entrevistas sinalizaram a carência de construção de recursos didáticos na sala de aula nos cursos de graduação em geografia. Segundo elas, a construção dos modelos na pós-graduação se apresenta como uma alternativa na direção de superar este déficit e instrumentalizar os futuros mestres e doutores para enriquecer suas práticas pedagógicas. 0 Estudante 12 expõe:

Durante a construção dos recursos na sala de aula, inúmeras vezes comentamos da importância de, mesmo na pós-graduação, termos espaços na sala de aula para a construção de recursos didáticos. Em geral, os cursos de graduação em geografia não oferecem momentos como estes. Neste sentido, a pós-graduação pode nos auxiliar a superar esta deficiência. (Estudante 12, aluno de mestrado, 2015).

Todavia, como destaca Goulart (2014, p.28), "é no cotidiano da sala de aula que o trabalho se efetiva. Sem muito interesse, reflexão e estudo, pouco pode ser feito". Segundo a autora (p. 29), "a sala de aula precisa voltar a ter um lugar de destaque nos estudos teórico-práticos, não como espaço para olhar e criticar, mas para efetiva intervenção, ajudando os professores nas suas demandas cotidianas". Assim, as entrevistas evidenciaram que a construção de recursos em sala de aula pode apresentar-se como um diferencial na prática pedagógica e a utilização dos instrumentos adequados com objetivos traçados conduzem a aulas com mais qualidade, capaz de envolver os estudantes no processo de ensino e de aprendizagem.

\section{Considerações Finais}

O presente estudo analisa a percepção de estudantes a respeito da construção, em sala de aula, de recursos didáticos aplicados à educação geográfica na pós-graduação em geografia.

Evidenciou-se que a construção dos recursos didáticos em sala de aula facilita a compreensão dos conteúdos e conceitos mediados, à medida que em cada construção é necessário o entendimento dos princípios teóricos-metodólogicos de cada recurso. Além disso, comprovou-se que as aulas tornam-se mais atrativas, dinâmicas, aliando ações integradoras entre teoria e prática.

Constatou-se que a construção de recursos em sala de aula promove maior interação entre os envolvidos facilitando a relação professor-aluno-conteúdo. Ocorre ampla discussão e troca de saberes entre os alunos e, entre estes e o professor. Assim, os estudantes participam ativamente do processo e o professor acompanha e realiza as intervenções durante toda a ação, assumindo a função de mediador do processo de ensino e de aprendizagem.

Revelou-se que há, entre os estudantes da pós-graduação em geografia, carência de formação para construção de recursos que já vem dos cursos de graduação em geografia. Tal fato reflete negativamente na atuação dos seus egressos, quando da atuação como professores. Neste caso, a pósgraduação é contributiva para superação do déficit destes estudantes. A partir da possibilidade de vivenciar a construção, os estudantes instrumentalizam-se para construir com seus alunos os recursos 
didáticos. Ademais, comprovou-se que o professor de geografia, em qualquer nível de ensino, deve possibilitar aos alunos espaços para a construção própria de instrumentos de aprendizagem.

Constatou-se que a sala de aula além de ser um espaço propício para que os estudantes desenvolvam a capacidade de construir seu próprio conhecimento, possibilita a promoção de situações potenciais de reflexão e estabelecimento de relação entre diversos contextos do dia a dia, ampliando seu saber. Assim, a prática de construção de recursos didáticos afasta o professor do papel de transmissor de informações e possibilita que, no processo de mediação, ele e seus alunos sejam produtores de conhecimento geográfico.

Comprovou-se que o professor de Geografia necessita pussuir atitude reflexiva em relação à educação geografia, e, a partir daí, utilizar e construir meios adequados e eficazes em suas aulas. Deste modo, a sala de aula se transforma em um espaço privilegiado de construção, discussão, questionamento, debate e de efetiva construção do conhecimento geográfico.

Por fim, evidenciou-se que os estudantes percebem o caráter eminentemente prático da disciplina em que ocorreu a construção dos recursos em sala de aula. Ademais, destacaram ao construir em sala de aula os recursos didáticos, instrumentaliza-os à construí-los com seus alunos, aprimorando sua prática pedagógica, desenvolvendo e ampliando suas noções de educação geográfica.

\section{Referências}

ALMEIDA, Rosângela Doin de. Do desenho ao mapa: iniciação cartográfica na escola. São Paulo: Contexto, 2001.

ALVES-MAZZOTTI, Alda Judith.; GEWANDSZNAJDER, Fernando. O método nas ciências naturais e sociais: pesquisa quantitativa e qualitativa. São Paulo: Pioneira, 1998.

ARCANJO. Jacineide. G. et al. Recursos didáticos e o processo de ensino e Aprendizagem.In: Anais IX Jornada de Ensino Pesquisa e Extensão UFRPE, Recife. 2009.

AZAMBUJA, Leonardo Dirceu de. Metodologias cooperativas para ensinar e aprender geografia. In: CALLAI, Helena Copetti et al. (Orgs.). Educação geográfica: reflexão e prática. Ijuí: Unijuí, 2011. p. 185210.

BOGDAN, Rober. C.; BIKLEN, Sari. K. Investigação qualitativa em educação: uma introdução à teoria e aos métodos. Lisboa: Porto Editora, 1994.

CALLAI, Helena Copetti. Em busca de fazer educação geográfica. In: CALLAI, Helena Copetti et al. (Orgs.). Educação geográfica: reflexão e prática. Ijuí: Unijuí, 2011. p. 15-33.

Estudar o lugar para compreender o mundo. In: CASTROGIOVANNI, Antonio Carlos (Org.). Ensino de Geografia: práticas e textualizações no cotidiano. 3. ed. Porto Alegre: Mediação, 2003a, p. 83134.

CASTROGIOVANNI, Antonio Carlos. Espaço Geográfico escola e seus Arredores. In: CALLAI, Helena Copetti. Educação Geográfica Reflexão e Prática. Ijuí: Ed. Unijuí, 2011.

Para entender a necessidade de práticas prazerosa no ensino de geografia na pósmodernidade. In: REGO, Nelson; CASTROGIOVANNI, Antonio Carlos; KAERCHER Nestor André. (Orgs.). Geografia Práticas Pedagógicas para o Ensino Médio. Porto Alegre: Artemed, 2007.

CASTROGIOVANNI, Antonio Carlos. Diferentes conceitos nas complexas práticas de ensino em geografia. In: TONINI, Ivaine Maria et al. (Orgs.). O ensino de geografia e suas composições curriculares. Porto Alegre: Mediação, 2014. p. 175-183.

Subir aos sótãos para descobrir a geografia. In: MARTINS, Rosa Elisabete Militiz Wypyczynki Martins, TONINI, Ivanine Maria; GOULART, Ligia Beatriz (Orgs.). Ensino de geografia no contemporâneo: experiências e desafios. Santa Cruz do Sul: EDUNISC, 2014. p. 85-101.

E agora, como fica o ensino da geografia com a globalização?. In: CASTROGIOVANNI, Antonio Calos et al. (Orgs). Geografia em sala de aula: práticas e reflexões. 4. ed. Porto Alegre: UFRGS, 2003. p. 83-85.

CASTELLAR, Sonia Maria Vanzella. Formação continuada mediada pelas pesquisas acadêmicas. In: SACRAMENTO, Ana Claudia Ramos, ANTUNES, Charlles de França, FILHO, Manoel Martins de Santana (Orgs.). Ensino de geografia produção do espaço e processos formativos. Rio de Janeiro: Consequência,

ParaOnde!?, Porto Alegre, v.10, n.2, p.78-84, 2018. Edição Especial com artigos publicados originalmente na XII ENANPEGE http://seer.ufrgs.br/paraonde 
2015. p. 11-32.

.Educação geográfica: a psicogenética e o conhecimento escolar. Cad. Cedes, Campinas, v. 25, n. 66, p. 209-225, maio/ago. 2005

CAVALCANTI, Lana de Souza. Jovens escolares e suas praticas espaciais cotidianas: o que tem isso a ver com as tarefas de ensinar Geografia? In: CALLAI, Helena Copetti. Educação Geográfica Reflexão e Prática. Ijuí: Ed. Unijuí, 2011.

. A geografia escolar e a sociedade brasileira contemporânea. In: TONINI, Ivaine Maria et al. (Orgs.). O ensino de geografia e suas composições curriculares. Porto Alegre: Mediação, 2014. p. 77-98.

. O ensino de geografia na escola. Campinas: Papirus, 2012.

Escola e Construção de Conhecimentos. Editora Papirus. São Paulo. 2010.

. A pesquisa colaborativa na formação de professores de geografia e seus desdobramentos no ensino. In: MARTINS, Rosa Elisabete Militiz Wypyczynki Martins, TONINI, Ivanine Maria; GOULART, Ligia Beatriz (Orgs.). Ensino de geografia no contemporâneo: experiências e desafios. Santa Cruz do Sul: EDUNISC, 2014. p. 138-150.

COSTELLA, Roselane Zordan. Ensinar o quê... para quê... quando... desafios da geografia na contemporaneidade. In: MARTINS, Rosa Elisabete Militiz Wypyczynki Martins, TONINI, Ivanine Maria; GOULART, Ligia Beatriz (Orgs.) Ensino de geografia no contemporâneo: experiências e desafios. Santa Cruz do Sul: EDUNISC, 2014. p. 188-205.

A Geografia Escolar e a Cidade ensaios sobre o ensino de Geografia para a vida urbana cotidiana. 3. ed. Campinas, Papirus. 2012.

FISCARELLI, Rosilene Batista de Oliveira. Material didático: discurso e saberes. Araraquara: Junqueira \& Martins Editoras, 2008.

FLICK, Uwe. Introdução à metodologia de pesquisa: um guia para iniciantes. Porto Alegre: Penso, 2013. GOULART, Ligia Beatriz. Aprendizagem e ensino: uma aproximação necessária à aula de geografia. In: TONINI, Ivaine Maria et al. (Orgs.). O ensino de geografia e suas composições curriculares. Porto Alegre: Mediação, 2014. p. 21-30

KAERCHER, Nestor André. Desafios e utopias no ensino de geografia. In: CASTROGIOVANNI, Antonio Carlos et al. (Orgs). Geografia em sala de aula: práticas e reflexões. 4. ed. Porto Alegre: UFRGS, 2003. p. 11-23.

MARTINS, Rosa Elisabete Militiz Wypycznski. A Prática de ensino de geografia como eixo articulador do processo formativo. In: MARTINS, Rosa Elisabete Militiz Wypyczynki Martins, TONINI, Ivanine Maria; GOULART, Ligia Beatriz (Orgs.). Ensino de geografia no contemporâneo: experiências e desafios. Santa Cruz do Sul: EDUNISC, 2014. p. 170-187.

NASCIMENTO, Rosemy da Silva. A hermenêutica de um mapa: a informação geográfica na materialização dos signos. In: MARTINS, Rosa Elisabete Militiz Wypyczynki Martins, TONINI, Ivanine Maria; GOULART, Ligia Beatriz (Orgs.). Ensino de geografia no contemporâneo: experiências e desafios. Santa Cruz do Sul: EDUNISC, 2014. p. 205-224.

. Estratégia de ensino-aprendizagem em Geografia através de recursos instrucionais - da maquete ao vídeo. In: 9 Encontro de prática e ensino de Geografia. Niterói: UFF, 2007.

ORLANDI, Eni P. Análise de Discurso: princípios e procedimentos. Campinas, SP: Pontes, 2003.

PONTUSCHKA, Nidia Nacib; PAGANELLI, Tomoko Iyada; CACETE, Núria Hanglei. Para Ensinar e Aprender Geografia. São Paulo. Cortez: 2009.

SACRAMENTO, Ana C. R. A mediação do conhecimento: a importância de se pensar o trabalho docente de Geografia. In: SACRAMENTO, Ana C. R., ANTUNES, Charlles de França, FILHO, Manoel Martins de Santana (Orgs.). Ensino de geografia produção do espaço e processos formativos. Rio de Janeiro: Consequência, 2015. p. 11-32.

SCHÄFFER, Neiva Otero et al. Um globo em suas mãos: práticas para a sala de aula. 2. ed. Porto Alegre: Editora da UFRGS, 2005.

SIBILIA, Paula. Redes ou paredes: a escola em tempos de dispersão. Rio de Janeiro: Contraponto, 2012. TONINI, Ivaine. Maria. Geografia escolar: uma história sobre seus discursos pedagógicos. Ijuí: Ed.Unijuí, 2. ed. , 2006.

YIN, Robert K. Estudo de caso - planejamento e métodos. 2. ed. Porto Alegre: Bookman. 2001.

ParaOnde!?, Porto Alegre, v.10, n.2, p.78-84, 2018. Edição Especial com artigos publicados originalmente na XII ENANPEGE http://seer.ufrgs.br/paraonde 